\title{
Water-Soluble Metal Working Fluids Additives Derived from the Esters of Acid Anhydrides with Higher Alcohols for Aluminum Alloy Materials
}

\author{
Syutaro Yamamoto ${ }^{1}$, Hideyuki Tomoda ${ }^{1}$ and Shoji Watanabe ${ }^{2 *}$ \\ ${ }^{1}$ NEOS Research Center (Ohike-cho, Konan, Shiga 520-3213, JAPAN) \\ ${ }^{2}$ Professor Emeritus of Chiba University, Department of Applied Chemistry, Faculty of Engineering (Present address: Akitsu 1-3-5-502, \\ Narashino, Chiba 275-0025, JAPAN)
}

\begin{abstract}
Water-soluble metal working fluids are used for processing of aluminum alloy materials. This short article describes properties of new additives in water-soluble metal working fluids for aluminum alloy materials. Many half esters or diesters were prepared from the reactions of higher alcohols with acid anhydrides. Interestingly, diesters of PTMG (tetrahydrofuran oligomer, $M W=650$ and 1000) and polybutylene oxide (MW = 650) with maleic anhydride and succinic anhydride showed both of an excellent anti-corrosion property for aluminum alloy and a good hard water tolerance. The industrial soluble type processing oils including these additives also showed anti-corrosion property and hard water tolerance.
\end{abstract}

Key words: water-soluble metal working fluids additives, aluminum alloy material, diesters of tetrahydrofuran oligomer, diesters of polybutylene oxide, hard water tolerance

\section{INTRODUCTION}

A variety of water-soluble metal working fluids are widely used for the processing of aluminum alloy materials similarly to the case of iron materials. It is well known that higher fatty acids such as oleic acid, ricinoleic acid and ricinoleic acid oligomers are used as one of the components of water soluble metal working fluids. Alkanolamines such as triethanolamine or diethanolamine are used to dissolve acidic ingredients into water, to increase anti-microbial activity of the fluids, and for other purposes. The long use of these fluids is apt to produce precipitates (for example, calcium salts of fatty acids) owing to calcium ion in hard water as well as heavy metals in aluminum alloy materials. Some patents on corrosion inhibitor in metal working and cutting of aluminum alloy materials are known. For example, a mixture of palm oil and oleic acid ${ }^{1)}$, ionic lithium compounds ${ }^{2}$, a polyalkyl ( $(\mathrm{N}$-aminoalkyl) iminoalkyl\}-siloxane ${ }^{3)}$, organic phosphonic esters ${ }^{4)}$, organic phosphoric esters ${ }^{4)}$, a mixture of castor oil phosphoric esters $^{5}$, and many others are made public.

Usually, these commercial water-soluble metal working fluids consist of many components, however the detailed compositions of these fluids have not been known. The additives which possess both an anti-corrosion property for aluminum and a good hard water tolerance have not been reported up to now. The present authors have been engaged in the syntheses of water-soluble metal working fluids additives and have published some patents ${ }^{6-8)}$ and some papers ${ }^{9)}$ on this subject. In this short article the authors describe the evaluations of some esters of higher alcohols with acid anhydrides as an aluminum corrosion inhibitor accompanying a good hard water tolerance.

\section{EXPERIMENTAL}

\subsection{Materials}

Abbreviations of raw materials used in this work and, in some cases, their sources are shown below. For polymer samples, the abbreviations are accompanied by numerals which indicate the average molecular weights of the polymer.

\footnotetext{
E-mail: s-wata@mui.biglobe.ne.jp

Accepted June 11, 2007 (received for review April 10, 2007)

Journal of Oleo Science ISSN 1345-8957 print / ISSN 1347-3352 online

http://jos.jstage.jst.go.jp/en/
}

* Correspondence to: Shoji Watanabe, Akitsu 1-3-5-502, Narashino, Chiba 275-0025, JAPAN 


\section{S. Yamamoto, H. Tomoda and S. Watanabe}

Tetrahydrofuran oligomer (PTMG, trade name; Mitsubishi Kagaku Co. Ltd.)

Polybutylene oxide (PBO, Mitsubishi Kagaku Co. Ltd.)

Blockcopolymer of propylene oxide and ethylene oxide (POEO, Sanyo Kasei Co. Ltd.: the average molecular weights are 1100, 2000 (PE-61), 2250 (PE-62), and 3000 (PE-64))

Polypropylene oxide (PO, Dow Chemical Co. Ltd.)

Polyethylene oxide (EO)

Blockcopolymer of butylene oxide and ethylene oxide with 1:1 molar ratio (BO-EO, NOF CORPORATION)

Maleic anhydride (MA)

Hexahydrophthalic anhydride (HHPA)

Succinic anhydride (SA)

Phthalic anhydride (PA)

Branched decanoic acid, $\mathrm{C}\left(\mathrm{R}_{1} \mathrm{R}_{2} \mathrm{R}_{3}\right) \mathrm{COOH}$ (NPG, trade name)

Oleyl Alcohol (Kyowa Technos Co. Ltd.; \#700 and \#900 mean that the samples contain $70 \%$ and $90 \%$ of oleyl alcohol, respectively)

\subsection{Reaction of PTMG 650 (I) with maleic anhydride (II)}

\subsubsection{Monoester (III)}

A mixture of PTMG 650 (I) (130 g, $0.2 \mathrm{~mol}$ ) and maleic anhydride (II) (19.6 g, $0.2 \mathrm{~mol}$ ) was heated with agitation at $140^{\circ} \mathrm{C}$ for $2 \mathrm{~h}$ and left overnight at room temperature (see Scheme 1). The degree of reaction was checked by IR spectrum.

When the absorptions of carbonyl group of (II) at 1779 and $1848 \mathrm{~cm}^{-1}$ disappeared and the strong absorption of an ester at $1729 \mathrm{~cm}^{-1}$ was recognized, the reaction was stopped. The product was nearly pure monoester (III) (150

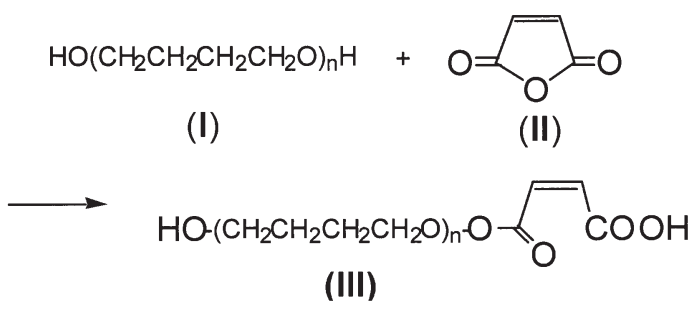

Scheme 1 Reaction of PTMG 650 (I) with Maleic Anhydride (II). $\mathrm{g}$, quantitative yield). The crude product was used for the test of metal working fluids additives without refining. This material $(1.0 \mathrm{~g})$ was chromatographed by short path column packed with silica gel using benzene as a solvent to give $0.7 \mathrm{~g}$ of compound (III). It showed the following spectral data: IR $\left(\mathrm{cm}^{-1}\right)$ : 3446, 1729, 1641, 1111, 820; $\operatorname{NMR}(\delta$, ppm): 1.62 [s, $\left.36 \mathrm{H},-\mathrm{CH}_{2}(\mathrm{a})-\right], 3.41$ [s, 32H, $\left.-\mathrm{OCH}_{2}(\mathrm{~b})-\right], 4.20$ [t, $\left.2 \mathrm{H},-\mathrm{CH}_{2}(\mathrm{c}) \mathrm{OH}, \mathrm{J}=6.6 \mathrm{~Hz}\right], 4.29\left[\mathrm{t}, 2 \mathrm{H},-\mathrm{CH}_{2}(\mathrm{~d}) \mathrm{OCO}, \mathrm{J}=6.36\right.$ $\mathrm{Hz}], 6.31[\mathrm{~d}, 1 \mathrm{H},-\mathrm{COCH}(\mathrm{e})=\mathrm{CHCOOH}, \mathrm{J}=11.0 \mathrm{~Hz}], 6.40$ [d, $1 \mathrm{H},-\mathrm{CH}=\mathrm{CH}(\mathrm{f})-\mathrm{COOH}, \mathrm{J}=11.0 \mathrm{~Hz}]$.

2.2.2 Diester (IV; see Scheme 3)

A mixture of PTMG 650 (I) (65 g, $0.1 \mathrm{~mol})$ and maleic anhydride (II) (19.6 g, $0.2 \mathrm{~mol}$ ) was heated with agitation at $150^{\circ} \mathrm{C}$ for $3 \mathrm{hrs}$ and left overnight at room temperature. With the progression of the reaction, the absorption in IR spectrum of the mixture due to carbonyl group of maleic anhydride (1779 and $\left.1848 \mathrm{~cm}^{-1}\right)$ diminished and finally disappeared, while the new absorption of an ester at $1724 \mathrm{~cm}^{-1}$ appeared. It is suggested that the product is nearly pure diester (IV) (yield $83 \mathrm{~g}$, quantitative yield). The crude product was used for the test of metal working fluids additives without refining. This product $(1.0 \mathrm{~g})$ was chromatographed by short path column packed with silica gel using toluene as a solvent to give $0.65 \mathrm{~g}$ of compound (IV). This substance was identified to be the diester (IV) from the following spectral data: IR $\left(\mathrm{cm}^{-1}\right)$ : $3446,1724,1287$, 1111, 743; NMR ( $\delta$, ppm): $1.62\left[\mathrm{~s}, 32 \mathrm{H},-\mathrm{CH}_{2}(\mathrm{a})-\right], 3.42[\mathrm{~s}$, $\left.32 \mathrm{H},-\mathrm{CH}_{2}(\mathrm{~b})-\right], 4.20\left[\mathrm{~m}, 4 \mathrm{H},-\mathrm{CH}_{2}(\mathrm{c}) \mathrm{CH}_{2} \mathrm{OCO}\right], 4.29$ [t, $4 \mathrm{H}$, $\left.\mathrm{J}=6.32 \mathrm{~Hz},-\mathrm{CH}_{2}(\mathrm{~d}) \mathrm{OCO}\right], 6.32[\mathrm{~d}, 2 \mathrm{H}, \mathrm{J}=11.0 \mathrm{~Hz},-\mathrm{CO}-$ $\mathrm{CH}(\mathrm{e})=\mathrm{CH}-\mathrm{COOH}], 6.40[\mathrm{~d}, 2 \mathrm{H}, \mathrm{J}=11.0 \mathrm{~Hz},-\mathrm{CH}=\mathrm{CH}(\mathrm{f})-$ $\mathrm{COOH}$.

Other monoesters and diesters were prepared by the reactions of each dibasic acid anhydride with each higher alcohol in a similar way, and they were also identified by IR, NMR and other indices. The products with maleic anhydride are listed in Table 1, and those with succinic anhydride, phthalic anhydride and hexahydrophthalic anhydride are shown in Table 2.

\subsection{Anti-corrosion test of aluminum alloy materials}

2.3.1 Preparation of sample solution

A sample solution (100 g) was prepared by dissolving 0.50 $\mathrm{g}$ of test materials (Tables 1 and 2 ) and $5.0 \mathrm{~g}$ of tri-
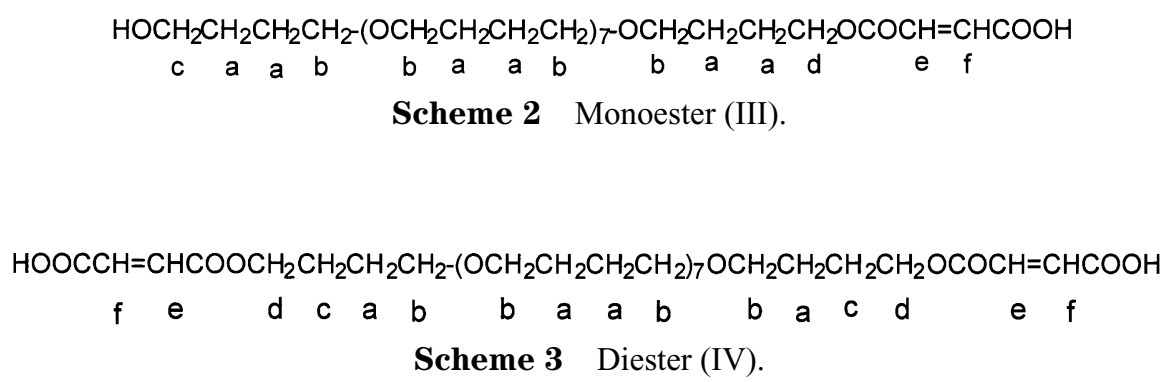
Table 1 Reaction Products of Various Alcohols with Maleic Anhydride and Their Anti-corrosion Tests for Aluminum and Hard Water Tolerance.

\begin{tabular}{|c|c|c|c|c|c|}
\hline $\begin{array}{l}\text { Entry } \\
\text { No. }\end{array}$ & Alcohols & $\begin{array}{l}\text { Acid } \\
\text { anhydride }\end{array}$ & $\begin{array}{l}\text { Molar } \\
\text { ratio }\end{array}$ & $\begin{array}{l}\text { Anti-corrosion test of } \\
\text { aluminum After } 24 \mathrm{hr}\end{array}$ & $\begin{array}{l}\text { Hard water tolerance } \\
\text { After } 24 \mathrm{hr}\end{array}$ \\
\hline 1 & PTMG 650 & MA & $1: 1$ & $\triangle$ & $x$ \\
\hline 2 & PTMG 650 & MA & $1: 2$ & (2) & (2) \\
\hline 3 & PTMG 1000 & MA & $1: 1$ & $\triangle$ & $x$ \\
\hline 4 & PTMG 1000 & MA & $1: 2$ & (a) & (a) \\
\hline 5 & PTMG 2000 & MA & $1: 1$ & $\triangle$ & $x$ \\
\hline 6 & PTMG 2000 & MA & $1: 2$ & $\triangle$ & $x$ \\
\hline 7 & PBO 650 & MA & $1: 1$ & $x$ & $\bigcirc$ \\
\hline 8 & PBO 650 & MA & $1: 2$ & (a) & (a) \\
\hline 9 & PBO 1000 & MA & $1: 2$ & (a) & $\bigcirc$ \\
\hline 10 & PBO 2000 & MA & $1: 2$ & $\triangle$ & - \\
\hline 11 & PE-61 & MA & $1: 1$ & $\times \times$ & (a) \\
\hline 12 & PE-61 & MA & $1: 2$ & $x \times$ & (a) \\
\hline 13 & PE-62 & MA & $1: 1$ & $x \times$ & (a) \\
\hline 14 & PE-64 & MA & $1: 1$ & $x \times$ & (a) \\
\hline 15 & PO 1000 & MA & $1: 2$ & $x$ & (a) \\
\hline 16 & PO 420 & MA & $1: 2$ & $\times$ & $\triangle$ \\
\hline 17 & PO (9) - EO (1) & MA & $1: 2$ & $\times$ & () \\
\hline 18 & Oleyl alcohol \#700 & MA & $1: 1$ & O & $\times$ \\
\hline 19 & Ricinoleic acid & MA & $1: 1$ & (a) & $x$ \\
\hline 20 & Ricinoleic acid dimer & MA & $1: 1$ & (a) & $\triangle$ \\
\hline 21 & Ricinoleic acid tetramer & MA & $1: 1$ & (a) & $x$ \\
\hline \multirow[t]{6}{*}{22} & 12-Hydroxystearic acid & MA & $1: 1$ & () & $x$ \\
\hline & Ricinoleic acid & & & () & $\times$ \\
\hline & NPG & & & $\times \times$ & () \\
\hline & Tall oil fatty acids & & & (a) & $\times$ \\
\hline & Undecylenic acid & & & $\triangle$ & $\times$ \\
\hline & Dodecanoic acid & & & $\triangle$ & $x$ \\
\hline
\end{tabular}

Detail of the procedure for anti-corrosion tests and hard water tolerance tests are shown in Experimental Section 2.3 and 2.4.

Entry No. 17: Weight ratio of $\mathrm{PO} / \mathrm{EO}$ is $9 / 1$.

The same results were obtained in all tests regardless of the quality of water, deionized water (hardness of 0 ) or city water (hardness of about 30).

ethanolamine into deionized water $(94.5 \mathrm{~g})$. This solution corresponds to the $0.50 \%$ solution of the test materials. The $\mathrm{pH}$ of these test solutions was adjusted at $9.0 \pm 0.2 \mathrm{by}$ adding boric acid or sodium hydroxide solution. Similarly, sample solutions were prepared with city water (Shiga, Japan; hardness 30).

2.3.2 Anti-corrosion test of aluminum pieces
Size of test piece of aluminum alloy $(\mathrm{ADC}-12)^{10)}$ is $6 \mathrm{~cm} \times 3$ $\mathrm{cm} \times 0.5 \mathrm{~cm}$. The test piece was washed with acetone, polished with emery paper (\# 240), and washed with acetone again, and then, was immersed $3 \mathrm{~cm}$ depth in each sample solution $\left(50 \mathrm{~cm}^{3}\right)$. After keeping for $24 \mathrm{~h}$ at $30^{\circ} \mathrm{C}$, the change of color on an aluminum piece surface was checked by visual observation. The corrosion-inhibiting effect was 
Table 2 Reaction Products of Various Alcohols with Some Acid Anhydrides, and Their Anti-corrosion Tests and Hard Water Tolerance.

\begin{tabular}{|c|c|c|c|c|c|}
\hline $\begin{array}{l}\text { Entry } \\
\text { No. }\end{array}$ & Alcohols & $\begin{array}{l}\text { Acid } \\
\text { anhydride }\end{array}$ & $\begin{array}{l}\text { Molar } \\
\text { ratio }\end{array}$ & $\begin{array}{l}\text { Anti-corrosion test of } \\
\text { aluminum After } 24 \mathrm{hr}\end{array}$ & $\begin{array}{l}\text { Hard water tolerance } \\
\text { After } 24 \mathrm{hr}\end{array}$ \\
\hline 23 & PTMG 650 & SA & $1: 2$ & () & (a) \\
\hline 24 & PBO 650 & SA & $1: 2$ & $\bigcirc$ & (a) \\
\hline 25 & Oleyl alcohol \# 700 & SA & $1: 1$ & $\bigcirc$ & $\triangle$ \\
\hline 26 & Oleyl alcohol \# 900 & SA & $1: 1$ & $\bigcirc$ & $\triangle$ \\
\hline 27 & Ricinoleic acid & SA & $1: 1$ & (a) & $\triangle$ \\
\hline 28 & Ricinoleic acid dimer & SA & $1: 1$ & (a) & $\triangle$ \\
\hline 29 & Ricinoleic acid tetramer & SA & $1: 1$ & $\bigcirc$ & $\triangle$ \\
\hline 30 & Ricinoleic acid hexamer & SA & $1: 1$ & $\triangle$ & $\triangle$ \\
\hline 31 & PBO 650 & PA & $1: 2$ & $\triangle$ & $\bigcirc$ \\
\hline 32 & PBO 1000 & $\mathrm{PA}$ & $1: 2$ & $x$ & - \\
\hline 33 & PTMG 650 & $\mathrm{PA}$ & $1: 2$ & $\triangle$ & O \\
\hline 34 & PTMG 1000 & $\mathrm{PA}$ & $1: 1$ & $\times \times$ & $\times$ \\
\hline 35 & PTMG 2000 & $\mathrm{PA}$ & $1: 2$ & $\triangle$ & $x$ \\
\hline 36 & Oleyl alcohol \#700 & $\mathrm{PA}$ & $1: 1$ & $\triangle$ & $x$ \\
\hline 37 & Ricinoleic acid & $\mathrm{PA}$ & $1: 1$ & (a) & $x$ \\
\hline 38 & Ricinoleic acid dimer & $\mathrm{PA}$ & $1: 1$ & $\bigcirc$ & $\triangle$ \\
\hline 39 & PBO 650 & HHPA & $1: 2$ & (a) & - \\
\hline 40 & PBO 1000 & HHPA & $1: 1$ & $x$ & - \\
\hline 41 & EO 1000 & HHPA & $1: 2$ & $x$ & (a) \\
\hline 42 & EO 1500 & HHPA & $1: 2$ & $x$ & (a) \\
\hline 43 & PO-EO (1100) & HHPA & $1: 1$ & $x \times$ & (a) \\
\hline 44 & PO (470) & HHPA & $1: 1$ & $x$ & (a) \\
\hline 45 & PE-61 & HHPA & $1: 1$ & $x \times$ & (a) \\
\hline 46 & PO (1000) & HHPA & $1: 1$ & $x$ & (a) \\
\hline 47 & BO-EO (1000) & HHPA & $1: 2$ & $x$ & 0 \\
\hline 48 & BO-EO (2000) & HHPA & $1: 2$ & $x$ & (a) \\
\hline 49 & Oleyl alcohol \#900 & HHPA & $1: 1$ & $\bigcirc$ & $x$ \\
\hline 50 & Behenic alcohol & HHPA & $1: 1$ & 0 & $x$ \\
\hline
\end{tabular}

Details of the procedure for anti-corrosion tests and hard water tolerance tests are shown in Experimental Section 2.3 and 2.4. Entry No. 47: Weight ratio of $\mathrm{BO} / \mathrm{EO}$ is $1 / 1$.

evaluated according to the following indexing.

() No appearance of discoloration of aluminum surface

A little discoloration of aluminum surface

$\triangle$ Gray

$\times \quad$ Dark gray

$\times \times$ Black

This test is a convenient method for the practical applica- tion in a factory.

\subsection{Hard water tolerance test}

2.4.1 Preparation of sample solution

A sample solution (100 g) was prepared by dissolving 0.50 $\mathrm{g}$ of test materials (Tables 1 and 2 ) and $5.0 \mathrm{~g}$ of triethanolamine into $\mathrm{CaCl}_{2}$ deionized water solution contain- 
ing $100 \mathrm{ppm} \mathrm{Ca}^{2+}$ ion $(94.5 \mathrm{~g})$. This solution corresponds to the $0.50 \%$ solution of the test materials. The $\mathrm{pH}$ of these test solutions was adjusted at $9.0 \pm 0.2$ by adding boric acid or sodium hydroxide solution.

2.4.2 Hard water tolerance test

The test solutions were maintained at $30^{\circ} \mathrm{C}$. After $24 \mathrm{~h}$, the presence of precipitates was observed with eyes. The effect of the additives on the hard water tolerance was evaluated according to the following indexing.

(a) No precipitates were observed.

A little precipitates were observed.

$\triangle$ Semitransparent

$\times \quad$ Many sediments were observed.

This test is a convenient method for the practical use in a factory, and would be sufficient to check the hard water tolerance of the test solution, although more quantitative analysis of precipitate formation such as turbidimetry may be available.

\section{RESULTS AND DISCUSSION}

Aluminum materials are apt to become blackish due to the corrosion of their surfaces. It is well known that sodium metasilicate is effective as corrosion inhibitor of aluminum materials ${ }^{11}$. However, the long-term safe keeping of the fluids containing sodium metasilicate is difficult because of the precipitate formation of inorganic compounds. Various higher fatty acids are commonly used as a component of water-soluble cutting fluids. Higher fatty acids have also anti-corrosion property for aluminum, but they have the following fault, just like the case of metasilicate. When these fluids containing higher fatty acids are diluted with hard-water and used for long hours, precipitates such as calcium salts of fatty acids are apt to form in coolant tank. This kind of precipitate formation becomes a serious problem in the storage and usage of metal cutting fluids, even though their quality is improved by the use of appropriate additives. Thus, in the present work, we concerned with the preparation of new additives in cutting fluids for aluminum alloy materials, which have both an anticorrosion property and a hard water tolerance, i.e., no precipitate formation.

The present authors have reported that the water-soluble metal working fluids containing half esters of dodecanedioic acid have excellent anti-corrosion properties for aluminum and iron ${ }^{8}$. It may safely be said that calcium salts of lower carboxylic acids are soluble in water. The present research was performed based on the idea that the replacement of one or two hydroxyl group in higher alcohols with lower carboxylic acid such as maleic anhydride may improve both the anti-corrosion performance for aluminum alloy and the hard water tolerance. Thus, a variety of half esters and diesters were prepared by the reactions of various hydroxyl compounds with some acid anhydrides. In addition, the evaluations of these esters as the additives for water-soluble metal working fluids of aluminum were performed.

The esters prepared in this work are listed in Tables 1 and 2. Anticorrosion performance for an aluminum alloy material was measured for each sample fluid containing various additives $(0.5 \% \mathrm{w} / \mathrm{w})$ as mentioned in Experimental Part. Sample fluids containing adducts, MA esters (Entry Nos. 2, 4, 8, 9, 19, 20, 21 and 22 in Table 1), SA esters (Nos. 23, 27 and 28 in Table 2), and other esters (Nos. 37 and 39 in Table 2) showed a good anti-corrosion property. In these cases, changes of color on aluminum test pieces were not recognized (Tables 1 and 2).

As for the hard water tolerance test in the presence of $\mathrm{Ca}^{2+}$ ion, sample fluids containing adducts, MA esters (Entry Nos. 2, 4, 8, 11, 12, 13, 14, 15 and 17 in Table 1) and other esters (Nos. 23, 24, 41, 42, 43, 44, 45, 46 and 48 in Table 2) showed good hard water tolerance. In these cases, no precipitates were recognized in their diluted solutions (Tables 1 and 2). Judging from the above results, it may be concluded that maleic acid diesters (IV) of PTMG 650 and PTMG 1000 (Nos. 2 and 4), MA diesters of PBO 650 (No. 8) and succinic acid diester of PTMG 650 (No. 23) enhance both of the anti-corrosion property for aluminum alloy materials and the hard water tolerance.

Industrial water-soluble metal working fluids were prepared by blending various additives as shown in Tables 3 . The fluids containing $0.20 \mathrm{wt} \%$ diester (Entry No. 8 and 9 in Table 3) and 0.25 wt\% diester (No. 2, 4 and 23 in Table 4) showed a good anti-corrosion property as well as a hard water tolerance.

\section{CONCLUSION}

The diesters of PTMG (650 and 1000) and PBO (650) with maleic anhydride and diester of PTMG (650) with succinic anhydride showed both anti-corrosion property for aluminum alloy materials and hard water tolerance.

\section{ACKNOWLEDGMENTS}

The author is thankful to Mr. T. Yoneshima, the head of the laboratory of NEOS Central Research Institute (Konan, Shiga, Japan) for his helpful supports. This research was performed in the laboratory of NEOS Central Research Institute.

\section{References}

1. Sakashita, S.; Nakayama, T. Japan Patent Publication 
Table 3 The Anti-corrosion Tests of Aluminum and Hard Water Tolerance of Industrial Water-soluble Metal Working Fluids Containing PBO Diesters.

\begin{tabular}{|c|c|c|c|c|}
\hline \multirow[t]{2}{*}{ Constituents } & \multicolumn{4}{|c|}{$\begin{array}{l}\text { Compositions of the } \\
\text { samples } 1 \sim 4 \text {, wt } \%\end{array}$} \\
\hline & 1 & 2 & 3 & 4 \\
\hline Monoisopropanolamine & 0.3 & 0.3 & 0.3 & 0.3 \\
\hline Triethanolamine & 2 & 2 & 2 & 2 \\
\hline Dodecanedioic acid & 0.3 & 0.3 & 0.3 & 0.3 \\
\hline 1, 2, 3 - Benzotriazole & 0.01 & 0.01 & 0.01 & 0.01 \\
\hline PO - EO blockpolymer & 2 & 2 & 2 & 2 \\
\hline Isononanoic acid & 0.3 & 0.3 & 0.3 & 0.3 \\
\hline Nonanoic acid & 0.2 & 0.2 & 0.2 & 0.2 \\
\hline PBO (650) + MA(1:2) Diester (Entry No.8) & 0.1 & 0.2 & 0.5 & \\
\hline PBO (1000) + MA(1:2) Diester (Entry No.9) & & & & 0.2 \\
\hline Water & 94.79 & 94.69 & 94.39 & 94.69 \\
\hline Anti-corrosion test for aluminum after $24 \mathrm{hr}$ & (a) & (a) & () & (a) \\
\hline Hard water tolerance after $24 \mathrm{hr}$ & (a) & (a) & ()) & 0 \\
\hline
\end{tabular}

The same results were obtained in all tests regardless of the quality of water, deionized water, city water, and deionized water containing $100 \mathrm{ppm} \mathrm{Ca}^{++}$ion.

Table 4 The Anti-corrosion Tests of Aluminum and Hard Water Tolerance of Industrial Water-soluble Metal Working Fluids Containing PTMG Diesters.

\begin{tabular}{|l|c|c|c|}
\hline \multicolumn{1}{|c|}{ Constituents } & \multicolumn{3}{c|}{ Compositions of the } \\
& \multicolumn{2}{c|}{ samples 1 $~ 3$, wt \% } \\
\hline N-Cyclohexyl-N,N-diethanolamine & 1 & 2 & 3 \\
\hline Triisopropanolamine & 0.5 & 0.5 & 0.5 \\
\hline$t$-Butylbenzoic acid & 0.5 & 0.5 & 0.5 \\
\hline 1,2,3-Benzotriazole & 0.25 & 0.25 & 0.25 \\
\hline 1,3-Bis(aminomethyl)cyclohexene & 0.01 & 0.01 & 0.01 \\
\hline NPG & 0.1 & 0.1 & 0.1 \\
\hline BO - EO copolymer & 0.5 & 0.5 & 0.5 \\
\hline PO polymer & 1.0 & 1.0 & 1.0 \\
\hline PTMG 650 +MA (1:2) Diester (Entry No. 2) & 1.5 & 1.5 & 1.5 \\
\hline PTMG 1000+ MA (1:2) Diester (Entry No. 4) & 0.25 & & \\
\hline PTMG 1000+ SA (1:2) Diester (Entry No. 23) & & 0.25 & \\
\hline Water & 95.39 & 95.39 & 95.39 \\
\hline Anti-corrosion test of aluminum after 24 hr & $(0$ & 0 & 0 \\
\hline Hard water tolerance after 24 hr & 0 & $\bigcirc$ & 0 \\
\hline
\end{tabular}

The same results were obtained in all tests regardless of the quality of water, deionized water, city water, and

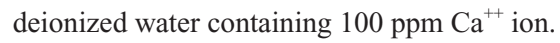


(A), 2000-129283 (2000).

2. Miyake, Y.; Mori, Y. Japan Patent Publication (A), 1997263976 (1997).

3. Maeda, A.; Shigehiro, K. Japan Patent Publication (A), 2000-26802 (2000).

4. Hayashi, N.; Shiotsuki, K. Japan Patent Publication (A), 2004-262960 (2004).

5. Nanbu, N. Japan Patent Publication (A), 2004-67770 (2004).

6. Yamamoto, S. Japan Patent Publication 2006-219613 (2006).

7. Yamamoto, S. Japan Patent Publication 2006-213982 (2006).
8. Tomoda, H.; Watanabe, S. Japan Patent Publication 2004-244683 (2004).

9. Kawato, Y.; Kamiusuki, T.; Watanabe, S. Water-soluble metal working fluids additives derived from the derivatives of 3-mercaptopropionic acid. J. Surfactants and Detergents 9 (4), 391-394 (2006).

10. Japanese Industrial Standard (1990) JIS H 5302; Aluminum alloys die castings (ADC 12) is an alloy composed of $\mathrm{Cu}(1.5 \sim 3.5 \%), \mathrm{Si}(9.6 \sim 12.0), \mathrm{Mg}$ (under 0.3), $\mathrm{Zn}$ (under 1.0), $\mathrm{Fe}$ (under 1.3), Mn (under 0.5), Ni (under 0.5), Sn (under 0.3) and $\mathrm{Al}$ (the rest).

11. Suga, K.; Watanabe, S. Yuhki Kogyo Kagaku, Yukagaku, 1st edn. Kohdansha. Tokyo. pp. 51-52 (1971). 